\title{
Involvement of the Olfactory Tubercle in Cocaine Reward: Intracranial Self-Administration Studies
}

\author{
Satoshi Ikemoto \\ Behavioral Neuroscience Branch, National Institute on Drug Abuse, National Institutes of Health, Department of Health and Human Services, Baltimore, \\ Maryland 21224
}

\begin{abstract}
Cocaine has multiple actions and multiple sites of action in the brain. Evidence from pharmacological studies indicates that it is the ability of cocaine to block dopamine uptake and elevate extracellular dopamine concentrations, and thus increase dopaminergic receptor activation, that makes cocaine rewarding. Lesion studies have implicated the nucleus accumbens (the dorsal portion of the "ventral striatum") as the probable site of the rewarding action of the drug. However, the drug is only marginally self-administered into this site. We now report that cocaine ( 60 or $200 \mathrm{~mm}$ in $75 \mathrm{nl} /$ infusion) is readily self-administered into the olfactory tubercle, the most ventral portion of the ventral striatum. Cocaine $(200 \mathrm{~mm})$ was self-administered marginally into the accumbens shell but not into the core, dorsal striatum, or ventral pallidum. In addition, cocaine injections ( $200 \mathrm{~mm}$ in $300 \mathrm{nl})$ into the tubercle but not the shell or ventral pallidum induced conditioned place preference. Rewarding effects of cocaine in the tubercle were blocked by coadministration of dopamine $\mathrm{D}_{1}$ or $\mathrm{D}_{2}$ antagonists ( $1 \mathrm{~mm} \mathrm{SCH} 23390$ or $3 \mathrm{~mm}$ raclopride) and were not mimicked by injections of the local anesthetic procaine (800 mu). In conclusion, the tubercle plays a critical role in mediating rewarding action of cocaine.
\end{abstract}

Key words: reinforcement; conditioned place preference; nucleus accumbens shell; core; ventral pallidum; dorsal striatum; procaine; dopamine $\mathrm{D}_{1}$ and $\mathrm{D}_{2}$ receptor antagonists; $\mathrm{SCH} 23390$; raclopride

\section{Introduction}

It is widely held that the rewarding effects of psychomotor stimulants such as amphetamine and cocaine are mediated by the nucleus accumbens (United States Department of Health and Human Services, 1999). Injections of amphetamine into the accumbens readily support robust self-administration (Hoebel et al., 1983; Phillips et al., 1994; Ikemoto and Sharpe, 2001) and induce conditioned place preference (Carr and White, 1986). Specific lesions of dopamine terminals in the accumbens disrupt self-administration of systemic amphetamine (Lyness et al., 1979) as well as conditioned place preference (Spyraki et al., 1982) induced by the drug. Although these findings suggest that amphetamine is mediated by the nucleus accumbens, evidence that cocaine is mediated in the same site is unconvincing.

Facilitation of dopamine transmission by blocking dopamine uptake (Ritz et al., 1987) plays a primary role in the rewarding effects of cocaine because cocaine is not rewarding to animals with selective pharmacological blockade of dopamine systems (De Wit and Wise, 1977; Ettenberg et al., 1982). One of the regions that receive dense dopaminergic projections is the nucleus accumbens. Several lines of evidence have suggested that the accumbens plays an important role in the rewarding effects of co-

\footnotetext{
Received July 8, 2003; revised Aug. 20, 2003; accepted Aug. 27, 2003.

This work was supported by the National Institute on Drug Abuse Intramural Research Program. I thank Dr. Roy Wise and Dr. Yavin Shaham for comments concerning this manuscript and Brian Witkin and Kathleen Donahue for technical assistance.

Correspondence should be addressed to Satoshi lkemoto, Behavioral Neuroscience Branch, National Institute on Drug Abuse, 5500 Nathan Shock Drive, Baltimore, MD 21224. E-mail: sikemoto@intra.nida.nih.gov.

Copyright $\odot 2003$ Society for Neuroscience $\quad$ 0270-6474/03/239305-07\$15.00/0
}

caine. Rewarding effects of systemic cocaine administration are decreased markedly by specific lesions of dopaminergic terminals in the accumbens (Roberts et al., 1977, 1979) or injections of dopamine antagonists into the accumbens (Maldonado et al., 1993; McGregor and Roberts, 1993; Baker et al., 1998). Systemic administration of cocaine increases extracellular dopamine in the accumbens (Imperato and Di Chiara, 1986; Pettit and Justice, 1989), among other regions (Hurd et al., 1988; Maisonneuve et al., 1990; Carboni et al., 2000; Sizemore et al., 2000). However, unlike amphetamine injections, direct injections of cocaine into the accumbens are only marginally rewarding (Carlezon et al., 1995; Liao et al., 2000; Rodd-Henricks et al., 2002) or are not rewarding at all (Goeders and Smith, 1983; Hemby et al., 1992).

Dopaminergic neurons from the ventral tegmental area also innervate densely to the olfactory tubercle (Voorn et al., 1986), localized just ventral to the accumbens. The olfactory tubercle is not merely an olfactory structure. With respect to its morphology, chemistry, and connections with other structures (Heimer, 1978), the tubercle has more in common with the accumbens and dorsal striatum than the primary olfactory cortex. It has been suggested that the tubercle and the accumbens should be conceptualized jointly as the ventral striatum (Heimer, 1978; Heimer et al., 1995). Thus, it is not surprising to see that dopaminergic manipulations of the tubercle have somewhat similar effects as those of the accumbens; it was recently found that injections of cocaine into the tubercle induce robust locomotion and rearing (Ikemoto, 2002; Ikemoto and Witkin, 2003). Because these behaviors may indicate the activation of a brain system that also mediates the rewarding effects of drugs and brain stimulation (Panksepp, 1982; Wise and Bozarth, 1987), we sought evidence of 
the rewarding effects of cocaine in the subregions of the ventral striatum and related regions. Here I report that cocaine injections into the anteromedial portion of the tubercle are robustly rewarding. Cocaine injections into other regions, including the accumbens, dorsal striatum, and ventral pallidum, were either marginally rewarding or not rewarding at all.

\section{Materials and Methods}

Animals. One hundred eleven male Wistar rats (Harlan, Dublin, VA; $250-350 \mathrm{gm}$ at the time of surgery) were used. Food and water were available ad libitum except during testing. The procedures were approved by the Animal Care and Use Committee of the National Institute on Drug Abuse Intramural Research Program and were in accordance with National Institutes of Health guidelines.

Surgery. Each animal was implanted with a unilateral guide cannula (24 gauge) that ended $1.0 \mathrm{~mm}$ above one of seven target sites (Ikemoto, 2002; Ikemoto and Wise, 2002). Efflux from central injections tends to follow a pressure gradient up the cannula shaft (Routtenberg, 1972). Accordingly, the cannulas for medial shell and anteromedial tubercle sites were inserted at a $20^{\circ}$ angle from the other hemisphere through the midline (Fig. 1A) to minimize diffusion of drug solution to the core or shell, respectively. The cannulas were inserted at a $10^{\circ}$ angle toward the midline for the site in the core, whereas guides were implanted vertically for injections in the anterolateral and posteromedial tubercle, ventral pallidum, and dorsal striatum. The incisor bar was set at $3.3 \mathrm{~mm}$ below the interaural line. The stereotaxic coordinates were $2.0 \mathrm{~mm}$ anterior to bregma (A), $2.0 \mathrm{~mm}$ lateral to the midline (L), and $8.5 \mathrm{~mm}$ ventral to the skull surface $(\mathrm{V})$ (measured along the trajectory of the angled cannula) for anteromedial tubercle placements; A 2.0, L 1.7, and V 7.2 for shell placements, A 2.0, L 2.0, and V 8.2 for anterolateral tubercle placements; A 2.0, L 3.5, and V 6.7 for core placements; A 0.6, L 2.0, and V 8.7 for posteromedial tubercle placements; A $0.6, \mathrm{~L} 2.0$, and V 7.7 for ventral pallidum placements; and A 1.0, L 3.0, and V 5.0 for dorsal striatum placements.

Drugs. (-)-Cocaine $\mathrm{HCl}$ (Research Triangle Institute, Research Triangle Park, NC), procaine $\mathrm{HCl}$ (Sigma, St. Louis, $\mathrm{MO}$ ), the dopamine $\mathrm{D}_{1}$ antagonist $R(+)-\mathrm{SCH} 23390 \mathrm{HCl}$ (Sigma), and the dopamine $\mathrm{D}_{2}$ antagonist $S(-)$-raclopride L-tartate (Sigma) were dissolved in artificial CSF consisting of (in mM): $148 \mathrm{NaCl}, 2.7 \mathrm{KCl}, 1.2 \mathrm{CaCl}_{2}$, and $0.85 \mathrm{MgCl}_{2}, \mathrm{pH}$ adjusted to $6.5-7.8$.

Operant conditioning procedure. For operant testing, each animal was placed in a $30 \times 22 \times 24 \mathrm{~cm}$ chamber equipped with a lever $(45 \mathrm{~mm}$ wide $\times 2 \mathrm{~mm}$ thick, protruding $20 \mathrm{~mm}$ from the wall) and a cue light just above the lever. Each rat's 31-gauge injection cannula was connected by polyethylene tubing to a micropump (Ikemoto and Sharpe, 2001) hanging a few millimeters above the rat's head. A lever press turned on the cue light for $1 \mathrm{sec}$ and the micropump for $5 \mathrm{sec}$, dispensing a $75 \mathrm{nl}$ infusion; additional lever presses were not rewarded until an additional $5 \mathrm{sec}$ passed after the completion of the infusion. The maximum number of infusions available per session was limited to 60 to minimize the possibility of tissue damage. Sessions lasted $90 \mathrm{~min}$ or until the rats received a total of 60 infusions.

To determine whether cocaine would be self-administered into specific regions, 68 rats with no previous operant training received $60 \mathrm{~mm}$ cocaine in sessions $2-4,200 \mathrm{~mm}$ in sessions 6 and 7, and vehicle in sessions 1,5 , and 8 . To determine whether cocaine reward was mediated by dopaminergic mechanisms, the effects of dopamine $\mathrm{D}_{1}$ and $\mathrm{D}_{2}$ antagonists SCH 23390 and raclopride and the local anesthetic procaine on intratubercle self-administration of cocaine were evaluated. Six rats with anteromedial tubercle guides were trained initially to lever press for 200 $\mathrm{mm}$ cocaine infusions in two or three sessions. In the $\mathrm{D}_{1}$ antagonist experiment, the rats received $200 \mathrm{~mm}$ cocaine plus $1 \mathrm{~mm} \mathrm{SCH} 23390,200$ mu cocaine, and vehicle over three sessions. In the $\mathrm{D}_{2}$ antagonist experiment, the animals received $200 \mathrm{~mm}$ cocaine plus $3 \mathrm{~mm}$ raclopride, 200 mu cocaine, and vehicle over three sessions. In the local anesthesia experiment, they received $800 \mathrm{~mm}$ procaine, $200 \mathrm{~mm}$ cocaine, and vehicle over three sessions. The order of testing the injection treatments in each experiment was counterbalanced among the subjects.
Two-lever discrimination procedure. Six rats with no previous operant training were placed in operant chambers with two retractable levers. The chambers were identical to the one-lever chambers described above, except that two levers were placed on a chamber wall. A response on the "active" lever resulted in a $5 \mathrm{sec}$ infusion ( $75 \mathrm{nl}$ in volume), turned on a cue light above the lever, and retracted both levers for $30 \mathrm{sec}$. A response on the "inactive" lever did not deliver infusions but retracted both the active and inactive levers for $30 \mathrm{sec}$. The left lever was designated the active lever for three rats and the inactive lever for the other three. Responding on the active lever produced vehicle infusions in session 1 and $200 \mathrm{~mm}$ cocaine infusions in sessions $2-4$. Sessions lasted 90 min or until the rats received a total of 60 infusions. Numbers of responses on each lever were recorded.

Conditioned place preference procedure. The place-conditioning chambers were configured as previously described (Ikemoto and Wise, 2002). In session 1, experimentally naive rats were placed individually in the place-conditioning chamber for $15 \mathrm{~min}$ without any treatment; they had access to both compartments, and the time spent in each compartment was recorded. In sessions $2-5$, they were placed individually in one of the compartments and received an intracranial injection (300 $\mathrm{nl}$ delivered over $60 \mathrm{sec}$ ) (Ikemoto, 2002; Ikemoto and Wise, 2002) of cocaine (200 $\mathrm{mm}$ ) or vehicle. An additional $30 \mathrm{sec}$ period elapsed before the injection cannula was removed. The animals remained in the compartment for an additional $5 \mathrm{~min}$ after the injection. Infusions of cocaine and vehicle were alternated over four sessions, as was the placement of each rat in one of the two compartments. The order of injection treatments and the assignment of the compartments with injection treatments were counterbalanced among the subjects. In session 6, the untreated rats were placed individually in the chamber and given access to both compartments; the time spent in each compartment was recorded for $15 \mathrm{~min}$. Sessions were separated by $24 \mathrm{hr}$.

Histology. When each rat completed the experimental procedure, the brain was removed and processed as described previously (Ikemoto, 2002; Ikemoto and Wise, 2002).

Statistical analyses. Effects of $60 \mathrm{~mm}$ cocaine on infusion rates were analyzed with $2 \times 2$ within-subjects ANOVAs with session and treatment (vehicle sessions 1 and 5 vs cocaine sessions 3 and 4). Effects of $200 \mathrm{~mm}$ cocaine were also analyzed with $2 \times 2$ within-subjects ANOVAs with session and treatment (vehicle sessions 5 and 8 vs cocaine sessions 6 and 7). The data on two-lever responses were analyzed with a $2 \times 4$ withinsubjects ANOVA with lever (active vs inactive lever) and session (1-4). Conditioned place preference data (times spent in compartments) were analyzed with $2 \times 2$ within-subjects ANOVAs with treatment (before vs after conditioning) and compartment (cocaine- vs vehicle-associated) for each injection site separately. Effects of dopamine antagonists or procaine on infusion rates were analyzed with one-way within-subjects ANOVAs over three treatments (experimental treatment, cocaine, and vehicle).

\section{Results}

\section{Cocaine self-administration}

We used a self-administration procedure to determine which region around the ventral striatum mediates the most robust rewarding effects of cocaine. Rats with indwelling cannulas aimed at one of seven regions (the anteromedial, anterolateral, and posteromedial tubercle, shell, core, dorsal striatum, and ventral pallidum; Fig. $1 A-C$ ) were placed in operant chambers and were trained to lever press for cocaine infusions. Rats learned to selfadminister $60 \mathrm{mM}$ cocaine into the anteromedial tubercle (Fig. $\left.2 A ; F_{(1,15)}=10.31 ; p<0.01\right)$. More robust self-administration was induced by $200 \mathrm{~mm}$ cocaine into the same region $\left(F_{(1,15)}=\right.$ $9.22 ; p<0.01)$. Both 60 and $200 \mathrm{~mm}$ cocaine supported persistent self-administration lasting the entire session or until the maximum number of infusions was obtained. However, vehicle infusions did not sustain self-administration (Fig. $2 B$ ). In the medial shell, $60 \mathrm{~mm}$ cocaine was not self-administered, whereas $200 \mathrm{mM}$ cocaine was self-administered moderately $\left(F_{(1,9)}=8.15 ; p<\right.$ 


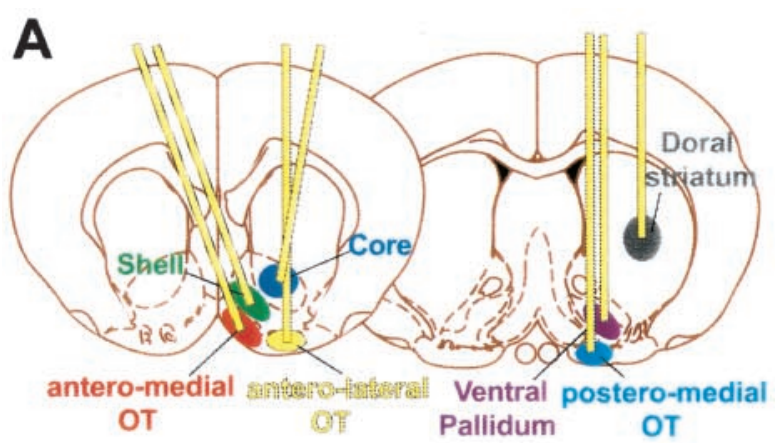

B

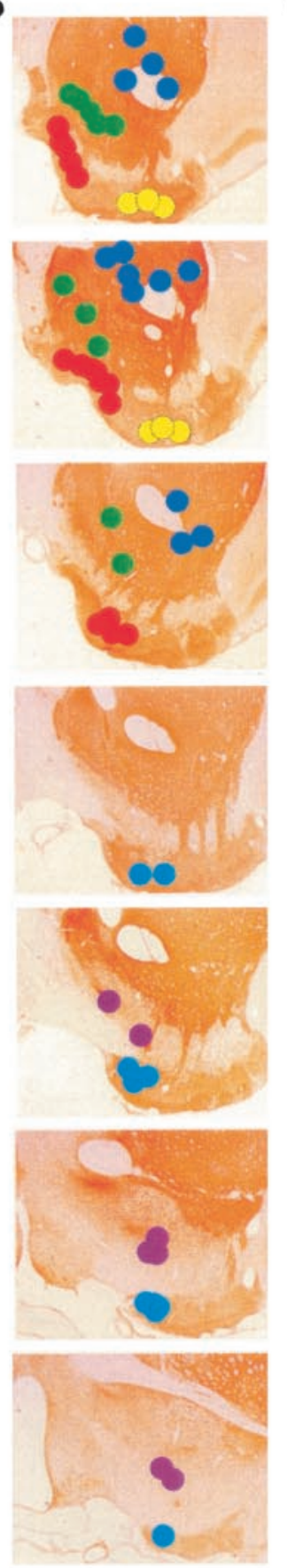

C
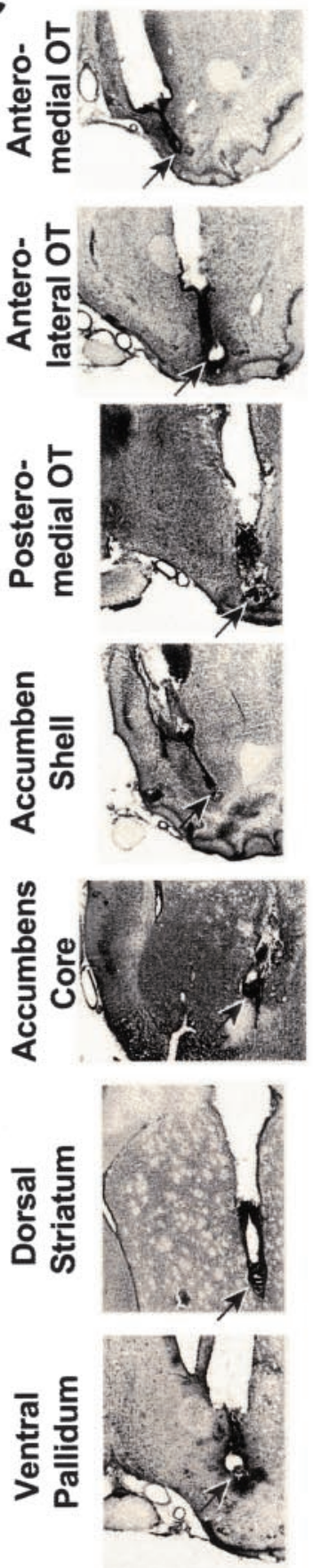

Figure 1. Injection sites of cocaine administration. $A$, Coronal sections (Paxinos and Watson, 1997) show target sites with cannula insertion angles. $B$, Histological results of all rats except the dorsal striatum subjects (for behavioral data, see Fig. 2) are summarized on tyrosine

\section{A antero-medial OT}
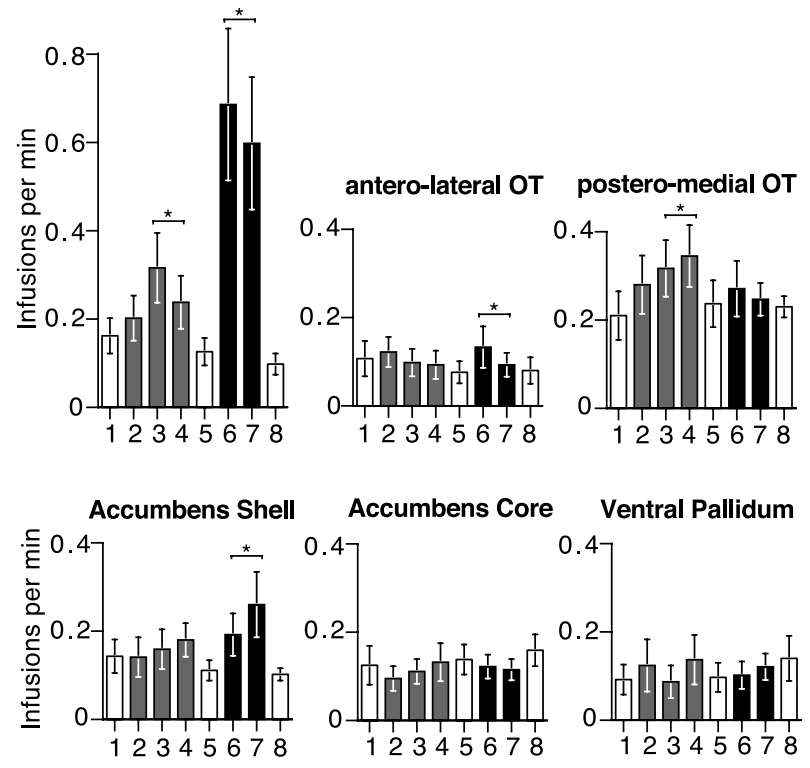

Ventral Pallidum

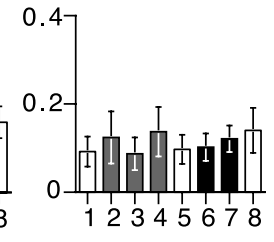

Dorsal Striatum

B

Session

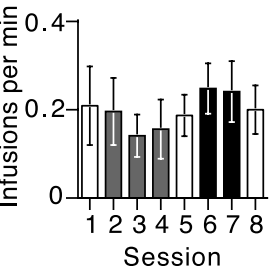

vehicle

$\square 60 \mathrm{mM}$ cocaine

$200 \mathrm{mM}$ cocaine

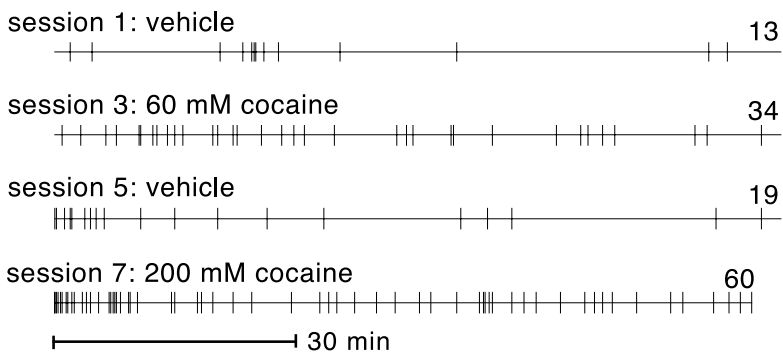

Figure 2. Intracranial self-administration of cocaine. $A$, Mean rates of cocaine selfadministration are shown separately for the target sites [anteromedial olfactory tubercle (OT), $n=16$; anterolateral $0 \mathrm{~T}, n=6$; posteromedial $0 \mathrm{~T}, n=10$; shell, $n=10$; core, $n=13$; pallidum, $n=7$; dorsal striatum, $n=6$ ]; Error bars indicate SEM. *Significant difference compared with respective vehicle sessions, $p<0.05$. $B$, Event records show representative patterns of self-administration into the anteromedial tubercle. Each vertical line on the horizontal line indicates the time point of an infusion. The number at the right of the horizontal line indicates total infusions in that session.

0.05). Similar concentration-dependent effects of cocaine were found in the anterolateral tubercle $\left(F_{(1,5)}=9.03 ; p<0.05\right)$. In the posteromedial tubercle, the low concentration of cocaine induced persistent self-administration $\left(F_{(1,9)}=20.54 ; p<0.005\right)$, whereas the high concentration did not. Cocaine did not support self-administration in the core, dorsal striatum, or ventral pallidum.

hydroxylase-stained sections. Color codes of the dots are consistent with those of the regions in A. C, Cresyl violet-stained sections show representative injection sites for target sites. OT, Olfactory tubercle. 


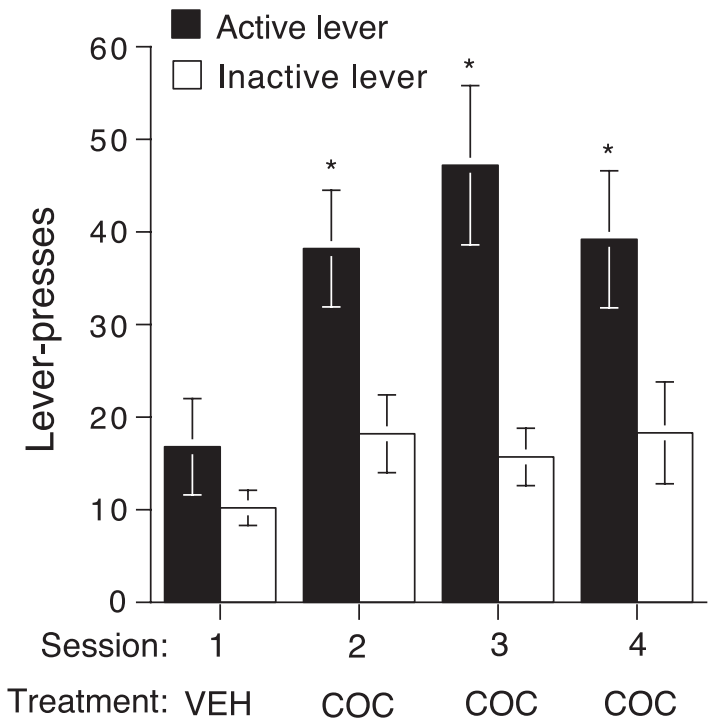

Figure 3. Two-lever discrimination. Rats $(n=6)$ did not respond on the active lever more than the inactive lever when active lever presses were rewarded with vehicle (VEH) in session 1. When active lever presses were rewarded with cocaine $(\mathrm{COC})$ in sessions $2-4$, they increased responding and responded on the active lever significantly more than the inactive lever. Data are mean lever presses per session; error bars indicate SEM. *Significant difference compared with inactive lever counts, $p<0.01$.

\section{Two-lever discrimination}

When active lever responding triggered vehicle infusions in session 1 , the rats did not respond on the active lever more than the inactive lever (Fig. 3). When active lever responding triggered cocaine infusions in sessions $2-4$, the animals responded on the active lever significantly more than the inactive lever. These observations are confirmed by a significant interaction between lever and session $\left(F_{(3,15)}=4.92 ; p<0.05\right)$ followed by simple effects comparisons between the two levers.

\section{Conditioned place preference}

To provide independent evidence for the apparent rewarding action of cocaine in the tubercle, we used a conditioned place preference procedure to assess the conditioned effects of cocaine in the absence of the unconditional effects of the drug. After the association of one test chamber compartment with cocaine injection and the other with vehicle, we measured the animals' preference for each compartment under a cocaine-free state. Rats receiving injections into the anteromedial tubercle spent more time in the cocaine-associated compartment (Fig. 4; a significant interaction between before and after conditioning and cocaine and vehicle compartments, $\left.F_{(1,9)}=7.01 ; p<0.05\right)$. On the other hand, rats receiving injections into the accumbens shell or ventral pallidum did not spend more time in the cocaine-associated compartment (Fig. 4).

\section{Roles of local anesthesia and dopamine receptors in cocaine reward}

To examine the role of the local anesthetic effect of cocaine in the reward, we tested the drug procaine, which has similar anesthetic properties, to find out whether it would mimic cocaine reward. Although procaine has a chemical structure similar to that of cocaine, the drug is much less potent as a dopamine uptake blocker (Ritz et al., 1987; Woodward et al., 1995). Rats receiving $800 \mathrm{~mm}$ procaine, which is a concentration equipotent to $200 \mathrm{~mm}$ cocaine in blocking $\mathrm{Na}^{+}$channels (Creveling et al., 1983; Reith et

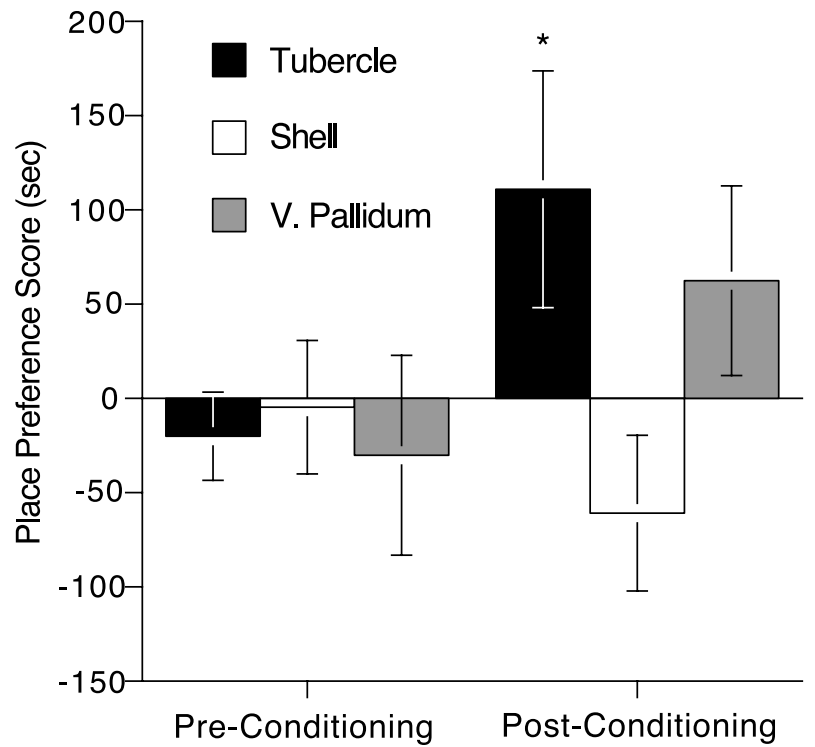

Figure 4. Conditioned place preference induced by cocaine injections ( $200 \mathrm{~mm}$ in $300 \mathrm{nl})$ into the anteromedial tubercle $(n=10)$ but not the shell $(n=10)$ or ventral (V.) pallidum $(n=11)$. Mean place preference scores (time spent in the drug-associated side - time spent in the vehicle-associated side) are shown; error bars indicate SEM. *Significant difference compared with baseline preference, $p<0.05$.

al., 1986; Wilcox et al., 1999), into the anteromedial tubercle decreased self-administration rates (Fig. $5 A ; F_{(2,10)}=5.02 ; p<$ $0.05)$. The temporal pattern of procaine self-administration resembled that of vehicle self-administration (Fig. $5 B$ ); that is, procaine injections induced extinction-like self-administration. To examine whether the rewarding effects of cocaine are mediated by dopaminergic mechanisms, the effects of dopamine receptor antagonists on cocaine self-administration were determined. Coadministration of the dopamine $\mathrm{D}_{1}$ or $\mathrm{D}_{2}$ receptor antagonists SCH 23390 (1 mM) and raclopride (3 mM) with cocaine decreased self-administration rates significantly (Fig. $5 A ; F_{(2,10)}=8.95 ; p<$ $0.01 ; F_{(2,10)}=4.98 ; p<0.05$, respectively). When the cocaine solution containing the $\mathrm{D}_{1}$ or $\mathrm{D}_{2}$ antagonist was given, selfadministration did not typically persist throughout the session (Fig. 5B).

\section{Discussion}

The present study suggests that the tubercle mediates rewarding effects of cocaine. This conclusion is elaborated below with considerations of the issues concerning behavioral assay and pharmacology and the anatomy of cocaine reward.

\section{Arousing effects of cocaine}

Injections of cocaine into the tubercle induce marked, unconditional locomotion and rearing (Ikemoto, 2002). The effective trigger zones of such responses parallel those in which cocaine induced rewarding effects. Significant locomotion and rearing are induced after cocaine administration into the anteromedial, anterolateral, or posterior tubercle or medial shell but not the lateral shell, core, or ventral pallidum (Ikemoto, 2002). Concentrations of cocaine that induce such responses are similar to the concentrations that induce rewarding effects. These findings arguably suggest that cocaine-induced arousal alone could be responsible for sustained lever press responding.

Two lines of evidence suggest that cocaine administration into the tubercle is reinforcing. When given a choice between two levers, rats responded selectively to the lever that delivered co- 


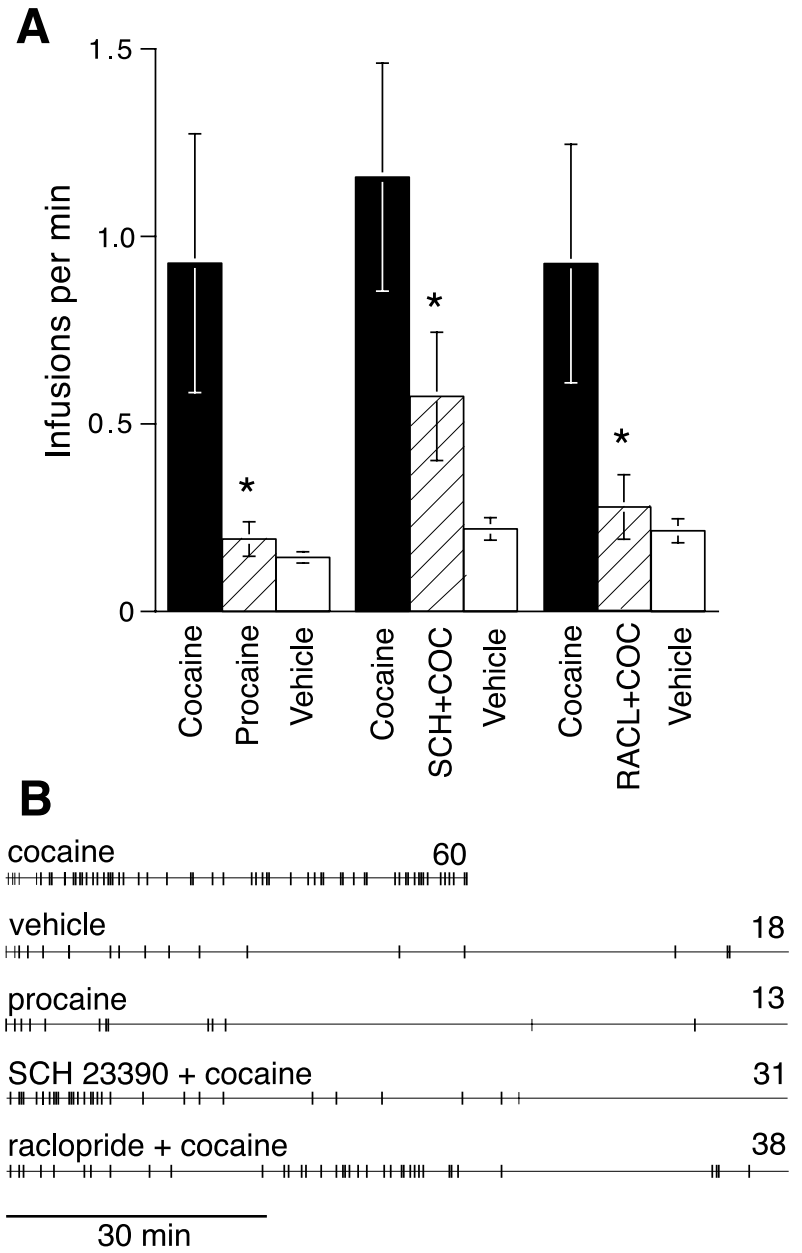

Figure 5. Roles of local anesthesia and dopamine receptors in cocaine reward. $A$, Data ( $n=$ 6) are mean infusion rates; error bars indicate SEM. *Significant difference compared with respective cocaine session, $p<0.05$. $B$, Event records show representative patterns of selfadministration into the anteromedial tubercle. The local anesthetic procaine $(800 \mathrm{~mm}$; an concentration equipotent to $200 \mathrm{~mm}$ cocaine in blocking $\mathrm{Na}^{+}$channels) did not sustain selfadministration $(A, B)$. Coadministration of the $\mathrm{D}_{1}$ antagonist $\mathrm{SCH} 23390(\mathrm{SCH}+\mathrm{COC})$ or the $\mathrm{D}_{2}$ antagonist raclopride ( $\mathrm{RACL}+\mathrm{COC})$ did not sustain self-administration $(A, B)$.

caine infusions. In addition, when cocaine or vehicle administration was paired with specific chamber compartments, rats preferred the cocaine-paired compartment. Place preference conditioned by cocaine injections was assessed when animals were free from unconditional (i.e., arousing) effects of the drug. These findings are consistent with the positive reinforcing effects of cocaine. Cocaine-induced locomotion and rearing may reflect positive emotion and motivation.

\section{Roles of local anesthesia and dopamine receptors in cocaine reward}

The local anesthetic action of cocaine does not appear to be involved in its rewarding effects. It has been suggested that the inhibition of medium spiny neurons in the accumbens is rewarding (Carlezon and Wise, 1996). Accordingly, cocaine administration might have been rewarding because it inhibits medium spiny neurons in the tubercle via its local anesthetic property. Local anesthesia is mediated by the inhibition of $\mathrm{Na}^{+}$channels. Injections of the local anesthetic procaine (at a concentration equipotent to a rewarding cocaine concentration in inhibiting $\mathrm{Na}^{+}$ channels) did not induce cocaine-like effects but did induce vehicle-like effects.
The rewarding effects of intratubercle cocaine administration appear to depend on dopamine transmission, requiring both $\mathrm{D}_{1}$ and $\mathrm{D}_{2}$-like receptors. Coadministration of the $\mathrm{D}_{1}$ and $\mathrm{D}_{2}$ antagonists with cocaine did not sustain self-administration throughout the session. The pattern of the self-administration resembled that of vehicle self-administration.

\section{Neuroanatomy of cocaine reward}

Comparisons of the effects of cocaine among injection sites indicate that the tubercle, particularly the anteromedial portion, mediates the most robust rewarding effects of the drug. Cocaine administration into the medial shell was less rewarding than administration into the tubercle. The present results are consistent with recent findings in that cocaine injections into the medial shell but not the core are moderately rewarding, as reflected in rates of self-administration (Carlezon et al., 1995; RoddHenricks et al., 2002). Liao et al. (2000) reported that cocaine injections at $600 \mathrm{~mm}$ (bilaterally) but not $300 \mathrm{~mm}$ into the shell induced conditioned place preference (CPP). The present study found that $200 \mathrm{~mm}$ cocaine injections into the tubercle but not the shell induced CPP. The fact that a higher cocaine concentration was needed to induce CPP via shell injections (Liao et al., 2000) than tubercle injections (present study) is consistent with the present self-administration findings.

A previous study (Gong et al., 1996) suggests that bilateral injections of cocaine into the ventral pallidum induce CPP. The present study, on the other hand, found that injections of cocaine into the ventral pallidum did not induce CPP or support selfadministration. Because there were no injection site controls in the study by Gong et al. (1996), the exact action site of cocaine studied is unclear. It is possible that ventral pallidal CPP (Gong et al., 1996) resulted from the diffusion of cocaine into the tubercle, which is located just ventral to the ventral pallidum. Indeed, the study by Gong et al. (1996) used a higher concentration (300 mM) and a larger volume $(500 \mathrm{nl} /$ hemisphere $\times 2)$ of cocaine with a longer conditioning trial duration $(30 \mathrm{~min})$ than those used in the present study (200 mM concentration, a single $300 \mathrm{nl}$ volume, 5 min conditioning trial duration for place conditioning; 60 and $200 \mathrm{~mm}$ concentrations and $75 \mathrm{nl}$ volume/infusion for self-administration).

Goeders and Smith $(1983,1986)$ and Goeders et al. (1986) showed that rats self-administer cocaine into the medial prefrontal cortex. Cocaine self-administration into the medial prefrontal cortex differs markedly from self-administration into the tubercle (examined in the present study) with respect to effective concentrations and rates of self-administration. Although much lower concentrations (between 0.5 and $1 \mathrm{~mm}$ ) of cocaine are self-administered into the prefrontal cortex than into the tubercle, rates of prefrontal cortex self-administration are remarkably low, at $\sim 0.05$ infusions/min (Goeders et al., 1986). This low rate may reflect a small rewarding effect of cocaine in the medial prefrontal cortex. Indeed, subsequent studies suggest that lesions of dopaminergic terminals or cell bodies in the medial prefrontal cortex do not disrupt or even facilitate the acquisition and maintenance of intravenous self-administration of cocaine (MartinIverson et al., 1986; Schenk et al., 1991; McGregor et al., 1996; Weissenborn et al., 1997). The medial prefrontal cortex does not appear to mediate the rewarding effects of systemic cocaine administration.

\section{Role of the nucleus accumbens in cocaine reward}

There have been many studies devoted to the investigation of the role of the accumbens in cocaine reward and addiction, based on 
the assumption that the accumbens plays a major role in these processes. In the present study, cocaine administration was more rewarding in the tubercle than in the accumbens. In light of this finding, it is necessary to reconsider the exact role of the accumbens in cocaine reinforcement. We will consider possible roles of the accumbens in the rewarding effects of cocaine in terms of an integrative zone and a trigger zone. It is important to recognize the difference between the anatomical substrates initiating reward process after direct interaction with cocaine (trigger zones) and the anatomical substrates integrating reward signals initiated somewhere else (integrative zones). The accumbens appears to play an important role in incentive learning involving a number of reinforcers, such as food, water, and sexual intercourse (Robbins and Everitt, 1996; Ikemoto and Panksepp, 1999). Therefore, although the accumbens may or may not be a major trigger zone for the rewarding effects of cocaine, it is likely that the accumbens is important for integrating the reward signals of cocaine, which may be triggered elsewhere. Such integrative zones likely include many brain regions, for example, the ventral pallidum.

The accumbens may still be a major trigger zone of cocaine after systemic treatment despite marginal rewarding effects after direct injections. Two factors should be considered: the local anesthetic action of the drug and delivery method used to administer cocaine. The local anesthetic action of cocaine may have hindered the role of the accumbens as a trigger zone for the rewarding effects of cocaine. A recent study (Ikemoto and Witkin, 2003) suggests that core neurons are more vulnerable to the local anesthetic effects of cocaine than tubercle neurons. Injections of the local anesthetic procaine into the core inhibit spontaneous locomotion as well as amphetamine-induced locomotion, whereas injections of the same procaine concentrations into the anteromedial tubercle do not disrupt spontaneous or amphetamine-induced locomotion (Ikemoto and Witkin, 2003). The concentrations of procaine inducing such locomotor disruption in the core are equipotent in inhibiting sodium channels to the cocaine concentrations that are rewarding in the tubercle.

The manner in which cocaine affects accumbens neurons via systemic administration likely differs from the effect of the drug when it is administered centrally. Systemic administration, which saturates the entire body with cocaine, makes the drug available for much longer periods, with a more gradual concentration change than intracranial administration, which diffuses rapidly to an insignificant concentration. Lower concentrations (at which cocaine has no local anesthetic action) may be rewarding after prolonged exposure to the accumbens. Thus, it is quite possible that the accumbens plays a more important role in mediating the rewarding effects of systemic cocaine than that found in the present intracranial administration study.

\section{Future investigation}

Only a handful of studies have examined the role of the tubercle in reward-related functions (Prado-Alcala and Wise, 1984; Fibiger et al., 1987; Clarke et al., 1990; Kornetsky et al., 1991; Stein and Fuller, 1992; Porrino et al., 2002). Because the tubercle appears to be involved in positive reinforcement of cocaine, the roles of the tubercle in the rewarding effects of other drugs of abuse, as well as learning and motivation involving natural rewards such as food and sex, should be examined. Further studies are needed to characterize the role of the tubercle in cocaine reward and addiction (e.g., molecular mechanisms). It is particularly important to examine the contribution of the tubercle to the rewarding effects of systemic cocaine administration. Although the lesion study done by Roberts et al. (1979) has been taken to support the role of the accumbens in cocaine reward, the lesions in question were quite extensive, affecting the tubercle as well as the accumbens (Roberts et al., 1979). It is necessary to conduct studies examining selective lesions in the accumbens or tubercle to evaluate the contribution of these regions in cocaine reward.

\section{References}

Baker DA, Fuchs RA, Specio SE, Khroyan TV, Neisewander JL (1998) Effects of intraaccumbens administration of SCH-23390 on cocaineinduced locomotion and conditioned place preference. Synapse 30:181-193.

Carboni E, Silvagni A, Rolando MT, Di Chiara G (2000) Stimulation of in vivo dopamine transmission in the bed nucleus of stria terminalis by reinforcing drugs. J Neurosci 20:RC102(1-5).

Carlezon Jr WA, Wise RA (1996) Rewarding actions of phencyclidine and related drugs in nucleus accumbens shell and frontal cortex. J Neurosci 16:3112-3122.

Carlezon Jr WA, Devine DP, Wise RA (1995) Habit-forming actions of nomifensine in nucleus accumbens. Psychopharmacology 122:194-197.

Carr GD, White NM (1986) Anatomical disassociation of amphetamine's rewarding and aversive effects: an intracranial microinjection study. Psychopharmacology 89:340-346.

Clarke PB, White NM, Franklin KB (1990) 6-Hydroxydopamine lesions of the olfactory tubercle do not alter $(+)$-amphetamine-conditioned place preference. Behav Brain Res 36:185-188.

Creveling CR, McNeal ET, Daly JW, Brown GB (1983) Batrachotoxininduced depolarization and $\left[{ }^{3} \mathrm{H}\right]$ batrachotoxinin-A 20 alpha-benzoate binding in a vesicular preparation from guinea pig cerebral cortex. Mol Pharmacol 23:350-358.

De Wit H, Wise RA (1977) Blockade of cocaine reinforcement in rats with the dopamine receptor blocker pimozide, but not with the noradrenergic blockers phentolamine or phenoxybenzamine. Can J Psychol 31:195-203.

Ettenberg A, Pettit HO, Bloom FE, Koob GF (1982) Heroin and cocaine intravenous self-administration in rats: mediation by separate neural systems. Psychopharmacology 78:204-209.

Fibiger HC, LePiane FG, Jakubovic A, Phillips AG (1987) The role of dopamine in intracranial self-stimulation of the ventral tegmental area. J Neurosci 7:3888-3896.

Goeders NE, Smith JE (1983) Cortical dopaminergic involvement in cocaine reinforcement. Science 221:773-775.

Goeders NE, Smith JE (1986) Reinforcing properties of cocaine in the medial prefrontal cortex: primary action on presynaptic dopaminergic terminals. Pharmacol Biochem Behav 25:191-199.

Goeders NE, Dworkin SI, Smith JE (1986) Neuropharmacological assessment of cocaine self-administration into the medial prefrontal cortex. Pharmacol Biochem Behav 24:1429-1440.

Gong W, Neill D, Justice Jr JB (1996) Conditioned place preference and locomotor activation produced by injection of psychostimulants into ventral pallidum. Brain Res 707:64-74.

Heimer L (1978) The olfactory cortex and the ventral striatum. In: Limbic mechanisms: the continuing evolution of the limbic system concept (Livingston KE, Hornykiewicz O, eds), pp 95-187. New York: Plenum.

Heimer L, Zahm DS, Alheid GF (1995) Basal Ganglia. In: The rat nervous system, Ed 2 (Paxinos G, ed), pp 579-628. San Diego: Academic.

Hemby SE, Jones GH, Justice Jr JB, Neill DB (1992) Conditioned locomotor activity but not conditioned place preference following intra-accumbens infusions of cocaine. Psychopharmacology 106:330-336.

Hoebel BG, Monaco AP, Hernandez L, Aulisi EF, Stanley BG, Lenard L (1983) Self-infusion of amphetamine directly into the brain. Psychopharmacology 81:158-163.

Hurd YL, Kehr J, Ungerstedt U (1988) In vivo microdialysis as a technique to monitor drug transport: correlation of extracellular cocaine levels and dopamine overflow in the rat brain. J Neurochem 51:1314-1316.

Ikemoto S (2002) Ventral striatal anatomy of locomotor activity induced by cocaine, D-amphetamine, dopamine and D1/D2 agonists. Neuroscience 113:939-955.

Ikemoto S, Panksepp J (1999) The role of nucleus accumbens dopamine in motivated behavior: a unifying interpretation with special reference to reward-seeking. Brain Res Rev 31:6-41.

Ikemoto S, Sharpe LG (2001) A head-attachable device for injecting nano- 
liter volumes of drug solutions into brain sites of freely moving rats. J Neurosci Methods 110:135-140.

Ikemoto S, Wise RA (2002) Rewarding effects of the cholinergic agents carbachol and neostigmine in the posterior ventral tegmental area. J Neurosci 22:9895-9904.

Ikemoto S, Witkin BM (2003) Locomotor inhibition induced by procaine injections into the nucleus accumbens core, but not the medial ventral striatum: implication for cocaine-induced locomotion. Synapse 47:117-122.

Imperato A, Di Chiara G (1986) Preferential stimulation of dopamine release in the nucleus accumbens of freely moving rats by ethanol. J Pharmacol Exp Ther 239:219-228.

Kornetsky C, Huston-Lyons D, Porrino LJ (1991) The role of the olfactory tubercle in the effects of cocaine, morphine and brain-stimulation reward. Brain Res 541:75-81.

Liao RM, Chang YH, Wang SH, Lan CH (2000) Distinct accumbal subareas are involved in place conditioning of amphetamine and cocaine. Life Sci 67:2033-2043.

Lyness WH, Friedle NM, Moore KE (1979) Destruction of dopaminergic nerve terminals in nucleus accumbens: effect on D-amphetamine selfadministration. Pharmacol Biochem Behav 11:553-556.

Maisonneuve IM, Keller RW, Glick SD (1990) Similar effects of D-amphetamine and cocaine on extracellular dopamine levels in medial prefrontal cortex of rats. Brain Res 535:221-226.

Maldonado R, Robledo P, Chover AJ, Caine SB, Koob GF (1993) D1 dopamine receptors in the nucleus accumbens modulate cocaine selfadministration in the rat. Pharmacol Biochem Behav 45:239-242.

Martin-Iverson MT, Szostak C, Fibiger HC (1986) 6-Hydroxydopamine lesions of the medial prefrontal cortex fail to influence intravenous selfadministration of cocaine. Psychopharmacology 88:310-314.

McGregor A, Roberts DC (1993) Dopaminergic antagonism within the nucleus accumbens or the amygdala produces differential effects on intravenous cocaine self-administration under fixed and progressive ratio schedules of reinforcement. Brain Res 624:245-252.

McGregor A, Baker G, Roberts DC (1996) Effect of 6-hydroxydopamine lesions of the medial prefrontal cortex on intravenous cocaine selfadministration under a progressive ratio schedule of reinforcement. Pharmacol Biochem Behav 53:5-9.

Panksepp J (1982) Toward a general psychobiological theory of emotions. Behav Brain Sci 5:407-467.

Paxinos G, Watson C (1997) The rat brain in stereotaxic coordinates, Ed 3. San Diego: Academic.

Pettit HO, Justice Jr JB (1989) Dopamine in the nucleus accumbens during cocaine self-administration as studied by in vivo microdialysis. Phamacol Biochem Behav 34:899-904.

Phillips GD, Robbins TW, Everitt BJ (1994) Bilateral intra-accumbens selfadministration of D-amphetamine: antagonism with intra-accumbens SCH-23390 and sulpiride. Psychopharmacology 114:477-485.

Porrino LJ, Lyons D, Miller MD, Smith HR, Friedman DP, Daunais JB, Nader MA (2002) Metabolic mapping of the effects of cocaine during the initial phases of self-administration in the nonhuman primate. J Neurosci 22:7687-7694.

Prado-Alcala R, Wise RA (1984) Brain stimulation reward and dopamine terminal fields. I. Caudate-putamen, nucleus accumbens and amygdala. Brain Res 297:265-273.

Reith ME, Kim SS, Lajtha A (1986) Structural requirements for cocaine congeners to interact with $\left[{ }^{3} \mathrm{H}\right]$ batrachotoxinin A 20-alpha-benzoate binding sites on sodium channels in mouse brain synaptosomes. J Biol Chem 261:7300-7305.

Ritz MC, Lamb RJ, Goldberg SR, Kuhar MJ (1987) Cocaine receptors on dopamine transporters are related to self-administration of cocaine. Science 237:1219-1223.

Robbins TW, Everitt BJ (1996) Neurobehavioural mechanisms of reward and motivation. Curr Opin Neurobiol 6:228-236.

Roberts DCS, Corcoran ME, Fibiger HC (1977) On the role of ascending catecholaminergic systems in intravenous self-administration of cocaine. Pharmacol Biochem Behav 6:615-620.

Roberts DCS, Koob GF, Klonoff P, Fibiger HC (1979) Extinction and recovery of cocaine self-administration following 6-hydroxydopamine lesions of the nucleus accumbens. Pharmacol Biochem Behav 12:781-787.

Rodd-Henricks ZA, McKinzie DL, Li TK, Murphy JM, McBride WJ (2002) Cocaine is self-administered into the shell but not the core of the nucleus accumbens of Wistar rats. J Pharmacol Exp Ther 303:1216-1226.

Routtenberg A (1972) Intracranial chemical injection and behavior: a critical review. Behav Biol 7:601-641.

Schenk S, Horger BA, Peltier R, Shelton K (1991) Supersensitivity to the reinforcing effects of cocaine following 6-hydroxydopamine lesions to the medial prefrontal cortex in rats. Brain Res 543:227-235.

Sizemore GM, Co C, Smith JE (2000) Ventral pallidal extracellular fluid levels of dopamine, serotonin, gamma amino butyric acid, and glutamate during cocaine self-administration in rats. Psychopharmacology 150:391-398.

Spyraki C, Fibiger HC, Phillips AG (1982) Dopaminergic substrates of amphetamine-induced place preference conditioning. Brain Res 253:185-193.

Stein EA, Fuller SA (1992) Selective effects of cocaine on regional cerebral blood flow in the rat. J Pharmacol Exp Ther 262:327-334.

United States Department of Health and Human Services (1999) Cocaine abuse and addiction. In: National Institute on Drug Abuse research report series. Washington, DC: National Institutes of Health 99-4342.

Voorn P, Jorritsma-Byham B, Van Dijk C, Buijs RM (1986) The dopaminergic innervation of the ventral striatum in the rat: a light- and electronmicroscopical study with antibodies against dopamine. J Comp Neurol 251:84-99.

Weissenborn R, Robbins TW, Everitt BJ (1997) Effects of medial prefrontal or anterior cingulate cortex lesions on responding for cocaine under fixed-ratio and second-order schedules of reinforcement in rats. Psychopharmacology 134:242-257.

Wilcox KM, Paul IA, Woolverton WL (1999) Comparison between dopamine transporter affinity and self-administration potency of local anesthetics in rhesus monkeys. Eur J Pharmacol 367:175-181.

Wise RA, Bozarth MA (1987) A psychomotor stimulant theory of addiction. Psychol Rev 94:469-492.

Woodward JJ, Compton DM, Balster RL, Martin BR (1995) In vitro and in vivo effects of cocaine and selected local anesthetics on the dopamine transporter. Eur J Pharmacol 277:7-13. 